\title{
ANÁLISE DA APLICAÇÃO DE METODOLOGIA DE APRENDIZAGEM BASEADA EM PROJETOS EM DISCIPLINA DO CURSO DE ENGENHARIA DE ALIMENTOS
}

Mariana Teixeira da Costa Machado - marianamachado210@gmail.com

Universidade Federal Rural do Rio de Janeiro, Departamento de Tecnologia de Alimentos

Rodovia BR 465, $\mathrm{km} 7$

23.890-000 - Seropédica - Rio de Janeiro

André Von Randow - avonrandow@gmail.com

Universidade Federal Rural do Rio de Janeiro, Departamento de Tecnologia de Alimentos

Rodovia BR 465, $\mathrm{km} 7$

23.890-000 - Seropédica - Rio de Janeiro

Erick Almeida Esmerino - erick.almeida@hotmail.com

Universidade Federal Rural do Rio de Janeiro, Departamento de Tecnologia de Alimentos

Rodovia BR 465, $\mathrm{km} 7$

23.890-000 - Seropédica - Rio de Janeiro

Resumo: Este trabalho relata a experiência da aplicação da metologia de aprendizagem baseada em projetos (PBL) nas disciplinas de operações unitárias do curso de graduação em Engenharia de Alimentos. O objetivo é ampliar o conhecimento da metodologia e contribuir para futuras aplicações e sistematização do mesmo. Através do projeto, procurou-se a aplicação contextualizada das teorias estudadas e o envolvimento ativo dos estudantes com discussões em grupo sobre as questões mencionadas anteriormente em sala. Para seu desenvolvimento, os alunos foram divididos em pequenos grupos, os quais precisavam realizar o dimensionamento das operações unitárias de uma indústria de óleo vegetal. Neste processo, existia a necessidade de buscar referências de diferentes fontes, ter pensamento crítico, colaborar com os colegas, ter boa comunicação e resolver problemas, estimulando, assim, um aprendizado mais aprofundado. Apesar de o método ser efetivo para desenvolver estas competências, sua aplicação apresentou diversas dificuldades, que são analisadas neste trabalho. Com o intuito de aprimorar a aplicação do método, ao final, são sugeridas correções e ajustes que possam promover o engajamento e o desenvolvimento das competências almejadas em todos os alunos da turma, pois se observou que este, como outras metodologias de aprendizagem ativas, é dinâmico e necessita de mudanças ao longo de todo o processo para sua melhoria contínua.

Palavras-chave: Educação superior. Metodologias ativas. Aprendizagem colaborativa.

\section{INTRODUÇÃO}

A Engenharia de Alimentos contempla de forma ampla a engenharia de processos, envolvendo equipamentos, fenômenos de transporte e operações de beneficiamento e processamento de alimentos, mas sem perder o foco na qualidade de produto. $\mathrm{O}$ setor possui constante inovação tanto em relação aos produtos quanto aos processos; assim, as operações unitárias constituem conceitos fundamentais para a transformação industrial de produtos alimentícios. Desta forma, os cursos de graduação em Engenharia de Alimentos possuem duas 
ou três disciplinas de operações unitárias, a fim de contemplar os diferentes processos presentes na indústria alimentícia. Estas disciplinas possuem como objetivo reconhecer a Operação Unitária empregada em cada processo e analisá-la, a fim de desenvolver o dimensionamento do equipamento e/ou otimização da operação, e propor o equipamento ou a modificação mais adequado(a) em termos de custo-benefício, mercado, qualidade do produto ou processo dentro da totalidade da indústria de alimentos. Os conteúdos programáticos compreendem as definições, os princípios de funcionamento e os cálculos de dimencionamento dos equipamentos envolvidos em cada operação unitária (trituração, filtração, agitação, centrifugação, secagem, absorção, extração, destilação, etc), que são relacionadas com a transferência de movimento, calor e/ou massa empregadas na indústria de alimentos.

As disciplinas de Operações Unitárias na Indústria de Alimentos geralmente são ministradas para discentes no sexto, sétimo e oitavo período do curso de graduação, pois os mesmos necessitam de conhecimentos prévios de cálculos, fenômenos de transporte, termodinânica, entre outros, para compreender e analisar os parâmetros envolvidos nos processos. Além disso, precisam considerar também as especificidades das matérias-primas, a qualidade do produto final a ser obtido e a qualidade e segunrança alimentar de cada operação. Desta maneira, os discentes necessitam de uma construção do conhecimento prévia, permitindo a interdisciplinaridade, ou seja, relembrando e conectando os conteúdos de diferentes disciplinas para aplicar a operação unitária estudada.

As principais habilidades e competências a serem desenvolvidas nas disciplinas são: Formular, analisar e solucionar problemas, utilizando métodos e ferramentas de engenharia; Conceber e projetar soluções criativas e desejáveis de engenharia e viáveis tecnicamente e economicamente; Determinar parâmetros produtivos e operacionais para as soluções; Desenvolver pensamento crítico e criativo; Desenvolver a comunicação oral, escrita e gráfica; Desenvolver a capacidade de trabalhar em equipe, com ética profissional, interação e comunicação; Desenvolver a autonomia para aprendizagem continua e atitude investigativa. Estas são algumas das competências preconizadas pela Resolução $\mathrm{n}^{0}{ }^{2}$, de 24 de abril de 2019, do Conselho Nacional de Educação (CNE/CES), que estabeleceu as Diretrizes Curriculares Nacionais do Curso de Graduação em Engenharia.

Deste modo, a fim de desenvolver estas capacidades, é essencial a realização de atividades que articulem simultaneamente a teoria, a prática e o contexto de aplicação, principalmente em trabalhos em grupo, envolvendo ainda interdisciplinaridade e integração dos conhecimentos. Para se atingir este propósito, pode-se utilizar metodologias para aprendizagem ativa. Entre elas, a aprendizagem colaborativa (Collaborative Learning) e a baseada em problemas (Problem-based learning ou Project-based learning) podem ser destacadas para serem trabalhados na engenharia, pois os métodos necessitam de amplo envolvimento dos alunos ao longo das disciplinas, de forma a cumprirem as metas propostas, buscando referências e conhecimentos prévios, pensando criticamente, desenvolvendo habilidade de organização, resolução de problemas, colaboração e comunicação, estimulando, assim, um aprendizado mais autônomo, aprofundado e tornando-os construtores ativos de seu próprio conhecimento.

Para aplicação da aprendizagem colaborativa e a baseada em problemas, foi realizado um projeto, em grupo, de uma indústria de alimentos, englobando as operações unitárias contidas em cada disciplina (Operações Unitárias na Indústria de Alimentos I e II) e diferentes matérias-primas, cada uma com sua especificidade, promovendo interdisciplinaridade, reflexão sobre os conhecimentos adquiridos previamente e busca novas informações, a fim de propor o equipamento e dimensionamento deste da forma mais adequada, e ainda atingir o 
melhor custo-benefício, atendendo ao mercado e qualidade do produto. O desenvolvimento deste projeto ao longo das disciplinas será discutido neste trabalho.

\section{REFERENCIAL TEÓRICO}

Um dos desafios atuais no ensino de Engenharia é conceber e implementar sistemas de ensino capazes de promover uma formação profissional em sintonia com o mercado de trabalho e com as inovações tecnológicas cada vez mais intensas. Diante destas mudanças, é notável, que além do conhecimento técnico e científico, ocorra uma formação multidisciplinar, que instrua os indivíduos a agirem de forma autônoma, ativa e inovadora pela busca de novas informações, estimulando a reflexão e análise crítica. Além disso, o profissional deve ter boa comunicação e ser capaz de trabalhar em equipes com distintas formações profissionais e culturais, e ainda possuir senso de responsabilidade social e ambiental. Estas são competências preconizadas pela Resolução $\mathrm{n}^{0} 2$ (CNE/CES), que também estabelece recomendações sobre atividades que articulem simultaneamente a teoria, a prática e o contexto de aplicação; trabalhos individuais e em grupo, sob orientação docente; interdisciplinaridade; atividades acadêmicas de síntese dos conteúdos, integração dos conhecimentos e articulação de competências; e o uso de metodologias para aprendizagem ativa.

A aprendizagem ativa é geralmente definida como qualquer método instrucional que envolva os alunos no processo de aprendizagem, tendo como elemento principal, o seu envolvimento ativo no processo de aprendizagem (PRINCE, 2004). Estas metodologias podem ser usadas como modelos pedagógicos com potencial para enfrentar os desafios atuais no ensino de Engenharia, pois, nestas, o aluno é o agente principal do processo de aprendizagem e da construção de seu conhecimento, enquanto o professor é um mediador e orientador desse processo (ELMÔR FILHO et al., 2019). Entretanto, apesar do professor ser apenas o mediador, o sucesso dessas novas estratégias de ensino-aprendizagem depende do entendimento e envolvimento docente no processo (FELDER; BRENT, 2003). Entre as estratégias e métodos de aprendizagem ativa, Felder e Brent (2003) apontam que a aprendizagem colaborativa (Collaborative Learning) e a baseada em problemas (Projectbased learning), são potenciais instrumentos para serem trabalhados na engenharia.

O aprendizado baseado em projetos é um método de ensino no qual os alunos adquirem conhecimento e habilidades trabalhando por um período prolongado (algumas semanas ou mais) para investigar e responder a uma questão, um problema ou um desafio, que seja autêntico, complexo, flexível (aberto a diferentes soluções) e preferencialmente envolvendo conteúdos multidisciplinares. Pode ser aplicado em uma disciplina ou em tópicos individuais, e devem exigir o conhecimento e o desenvolvimento das habilidades estabelecidas nos objetivos de aprendizado (FELDER; BRENT, 2003). O objetivo principal deste método é o envolvimento profundo do aluno, aplicando o conteúdo abordado de maneira significativa e com foco em um produto ou processo. Durante o desenvolvimento, há a necessidade de o aluno trabalhar em cooperação, planejar, pesquisar, pensar criticamente, defender seu ponto de vista, lidar com opiniões divergentes, organizar e executar o projeto (GÓMEZ-PABLOS et al., 2017).

Neste processo, o professor não deve fornecer instruções formais até que os alunos (possivelmente com alguma orientação) tenham gerado uma necessidade no contexto do problema. Na transição para aplicação deste método de ensino-aprendizagem, muitas práticas tradicionais permanecem, mas são reformuladas no contexto do projeto. Seu processo de implementação necessita de planejamento, avaliação da eficácia da aprendizagem, adaptações e/ou ajustes, para contínua melhoria de sua prática. Assim, a fim de auxiliar os educadores a 
projetarem e utilizarem a aprendizagem baseada em projetos, garantindo o engajamento dos alunos e o desenvolvimento de suas competências, o Instituto de educação PBLWorks desenvolveu dois guias: o primeiro apresenta os sete elementos essenciais para elaboração e desenvolvimento do projeto (Figura 1A), já o segundo, as sete práticas de ensino baseadas em projetos, orientando os professores a mensurar, calibrar e melhorar suas práticas (Figura 1B).

O primeiro guia (Figura 1A) expõe que o projeto deve ser estruturado por um problema, um desafio significativo ou ainda uma pergunta significativa a ser respondida. Entre as exigências para o desenvolvimento adequado, preconiza-se que estas questões centrais sejam aprendidas ao longo da disciplina, tenham mais de uma solução possível, com foco principal em um produto ou processo, e que estejam em nível apropriado de conhecimento prévio e alinhadas ao desenvolvimento das habilidades e competências que se almeja que os discentes alcancem no fim do projeto. Durante o mesmo, os alunos devem se envolver em um processo rigoroso e extenso de questionamentos, pesquisarem recursos e informações e aplicá-los, e para isso acontecer, o projeto deve ser autêntico e dentro do contexto do mundo real. Ao longo da disciplina, os alunos precisam ter voz, devem tomar decisões, sobre a forma de trabalho, selecionar as soluções mais apropriadas e criar e/ou aplicar, sob apenas a orientação de um instrutor (professor), e assim ocorrerá o desenvolvimento da análise crítica e da colaboração entre os estudantes. A eficiência do processo deve ser constantemente avaliada pelos envolvidos de modo a identificar obstáculos e aspectos que impossibilitem o desenvolvimento completo da atividade, e possibilitem reformulações/reestruturações. Desta maneira, os professores devem oferecer um retorno aos alunos, com críticas, para que os mesmos possuam a chance de revisar e aprimorar o trabalho. Do mesmo modo, os alunos devem apresentar suas percepções aos professores, para estes terem a oportunidade de aprimorar o processo de ensino-aprendizagem. Ao final do projeto, é recomendado que o processo ou produto gerado seja apresentado ao público, além da sala de aula.

Figura 1 - (A) Sete elementos essenciais para elaboração e desenvolvimento do projeto e (B) Sete práticas de ensino baseadas em projetos.
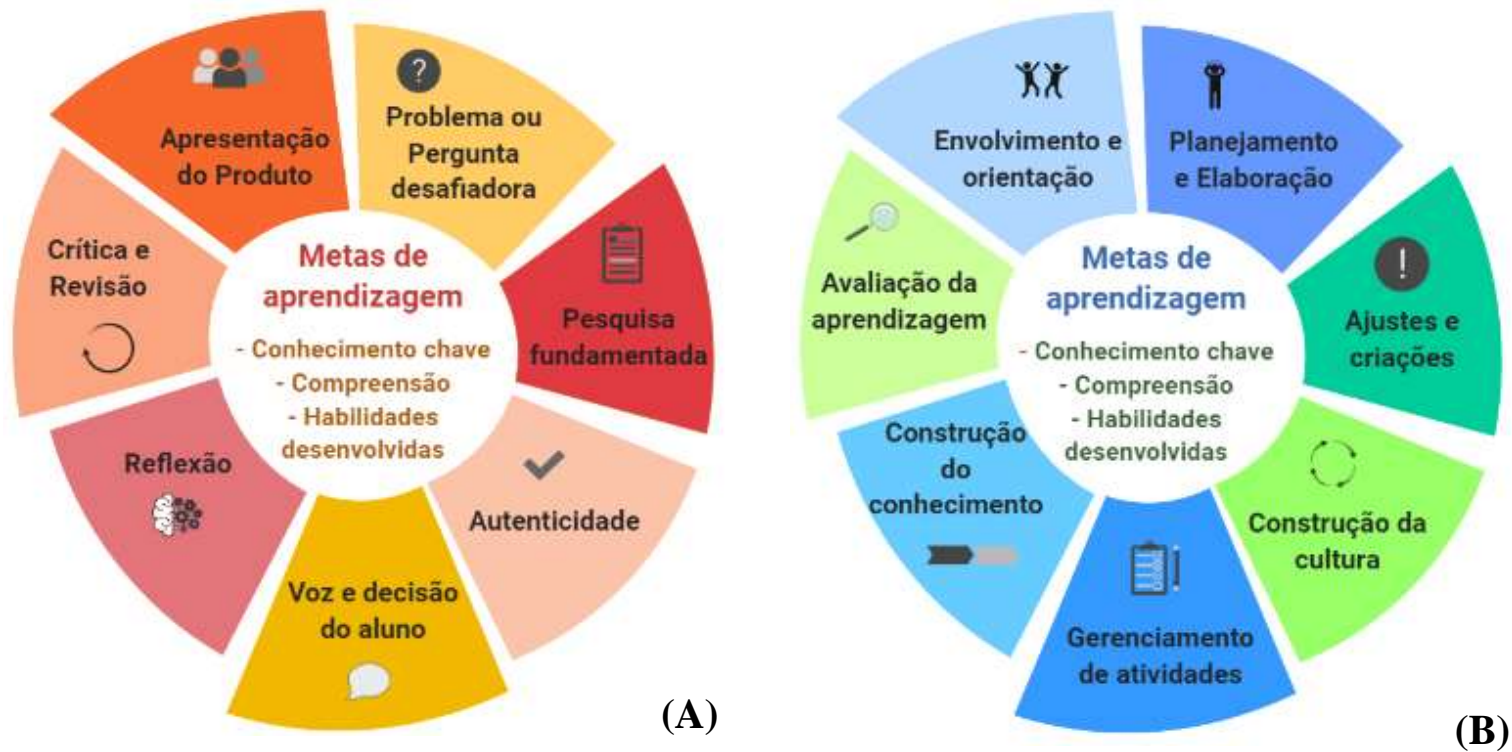

Fonte: Adaptada de PBLWorks.

O segundo guia (Figura 1B) discorre sobre práticas que os professores precisam executar para o ensino baseado em projetos. $\mathrm{O}$ primeiro passo é criar ou adaptar um projeto para um 
contexto real e planejar sua implementação, considerando suas experiências anteriores com práticas de ensino-aprendizagem e os níveis de conhecimento e experiências prévias dos alunos. Durante o curso ou disciplina, o professor deve fazer adaptações e ajustes no projeto, garantindo que este tenha foco na abordagem dos principais conteúdos e conhecimentos a serem trabalhados e no desenvolvimento das habilidades e competências almejadas. $\mathrm{O}$ professor deve desenvolver a cultura do aprendizado de forma autônoma, promovendo o envolvimento e estimulando o crescimento dos alunos. A responsabilidade de gerenciamento das atividades pode ser dividida com os estudantes, trabalhando juntos para organização das tarefas, definição de avaliações e de prazos. Ao longo do processo de aprendizagem, deve-se sempre ter em foco a construção do conhecimento, utilizando ferramentas para instruir, buscar e utilizar informações e recursos, e apoiar os alunos a alcançarem as metas do projeto, estimulando a realização das tarefas e o trabalho em equipe. Para aferir a aprendizagem, podese utilizar avaliações de habilidades, compreensão e conhecimento, incluindo a avaliação individual e por pares. Por fim, os professores devem instruir os discentes, promovendo engajamento.

Como pode ser observado, o professor, planeja, elabora e implementa o projeto, e durante a atividade, precisa construir a cultura e o conhecimento ao lado dos alunos. Entretanto, sem o envolvimento, trabalho e cooperação destes, o projeto não é efetivo para o processo de ensino-aprendizagem. $\mathrm{O}$ trabalho em pequenos grupos para a execução do projeto é essencial, e concomitantemente à aprendizagem baseada em projetos, desenvolve-se a aprendizagem colaborativa (Collaborative Learning), que tem como objetivo a promoção da interação entre os alunos e a cooperação para promover a aprendizagem (PRINCE, 2004).

Segundo Prince (2004), a colaboração pode promover uma ampla gama de resultados de aprendizagem dos alunos, como: interdependência positiva, na qual os membros da equipe são obrigados a confiar um nos outros para alcançar a meta que possuem em comum; responsabilidade individual, pois cada integrante tem obrigação por fazer sua parte do trabalho e pelo domínio de todo o material a ser aprendido; e os benefícios da interação (discussão, exposição de opiniões e feedbacks), embora algumas tarefas sejam divididas e realizadas individualmente. Adicionalmente, o uso apropriado de habilidades colaborativas, nas quais os alunos precisam desenvolver e praticar habilidades em comunicação, liderança, tomada de decisão, gerenciamento de conflitos, e a autoavaliação regular do funcionamento do grupo, na qual os membros da equipe avaliam periodicamente sua atuação dentre da mesma, identificando o que precisa ser mudado para o funcionamento mais eficaz no futuro, são resultados preconizados.

Diante do exposto, é notável que estes métodos de ensino-aprendizagem podem desenvolver várias competências estabelecidas na Resolução $\mathrm{n}^{\circ} 2$ (CNE/CES). A troca de experiências entre os professores pode auxiliar a entender como os mesmos lidam com essas novas abordagens em sua prática real de ensino, quais benefícios foram observados na sala de aula e em seus alunos, e que limitações e dificuldades foram encontradas. Esta abordagem e sua análise permitem que as estratégias de ensino-aprendizagem sejam aprimoradas, possibilitando a criação de um ciclo de melhoria contínua (GÓMEZ-PABLOS et al., 2017). Assim, o presente trabalho tem como objetivo apresentar a experiência e a análise da inserção da metodologia de aprendizagem baseada em projetos na disciplina de Operações Unitárias do curso de Engenharia de Alimentos de uma universidade pública brasileira.

\section{METODOLOGIA}

A experiência que será relatada foi desenvolvida no semestre de 2019.2 no contexto das disciplinas de Operações Unitárias na Indústria de Alimentos I e II, que são ofertadas no 
oitavo e nono períodos, respectivamente, no curso de graduação em Engenharia de Alimentos da Universidade Federal Rural do Rio de Janeiro, possuindo uma carga horária de 60 h cada, e ministradas por dois professores que dividem a carga horária das duas disciplinas. Procurouse com o projeto a aplicação contextualizada das teorias estudadas e o envolvimento dos estudantes em discussões em grupo sobre as questões mencionadas anteriormente em sala.

Para aplicação do método de aprendizagem baseada em projetos, foi definida uma indústria genérica de extração de óleo como objeto alvo do estudo. Os discentes foram divididos em grupos de quatro ou cinco indivíduos, onde cada grupo trabalhou com uma matéria-prima de origem vegetal (algodão, soja, arroz e canola), definida aleatoriamente na forma de sorteio. Foi disponibilizado um roteiro para orientação das etapas do projeto, assim como da entrega final, e explicitada a distribuição das notas das diferentes atividades da disciplina. Neste roteiro também estavam listadas referências bibliográficas de livros disponíveis na biblioteca. Além disso, foi apresentado um fluxograma geral das operações unitárias da indústria de extração de óleo, para orientação, que poderia ser alterado por cada grupo, conforme as necessidades e especificidades de cada matéria-prima e/ou produto.

Para cada operação unitária contida no conteúdo programático da disciplina, aulas expositivas foram ministradas para iniciar a relação entre objetivos e conteúdos. Ao final de cada conteúdo, os professores iniciavam a tarefa no ambiente virtual de aprendizagem que a Universidade possui. A tarefa permanecia aberta por quinze dias, sendo a entrega em formato digital no mesmo ambiente. No período de elaboração, os professores estavam disponíveis para encontrar os alunos de forma presencial, individualmente ou em grupo, quando necessário, para orientação ou discussão das questões propostas.

O foco principal do projeto era determinar o dimensionamento da indústria como um todo e sua viabilidade técnica, assim, após cada operação unitária ministrada, os estudantes deviam buscar a solução do dimensionamento, sendo esta uma questão de engenharia complexa, muitas vezes multidisciplinar. As questões possuíam fluência de ideias (pouco definidas e abertas), flexibilidade (variedade de soluções adequadas, pois poderiam, muitas vezes, fazer o dimensionamento de diferentes formatos) e originalidade, que requeriam síntese de conhecimentos que transcedem as fronteiras da disciplina, necessitando de pesquisa, análise e tomadas de decisões técnicas. Desta maneira, os estudantes deveriam planejar organizar e executar cada etapa do projeto, mas pensando no todo e na viabilidade técnica da indústria.

Após a entrega de cada parte do projeto, os professores apreciavam os trabalhos e realizavam comentários, no mesmo ambiente de aprendizagem. Assim, os alunos tinham o registro a cada tarefa, do documento entregue e dos comentários realizados, e podiam corrigir e/ou aprimorar o trabalho realizado. A cada certo número de Operações Unitárias ministradas uma avalição somativa era aplicada, com questões elaboradas de modo a levar o aluno a raciocinar sobre o conteúdo aprendido. Foram aplicadas duas e três provas para Operações Unitárias na Indústria de Alimentos I e II, respectivamente. Ao final do semestre, cada grupo apresentou a viabilidade técnica da indústria projetada, de forma oral e escrita, sucintamente, para o restante da turma e os professores da disciplina, momento, no qual também ocorreu uma avaliação.

\section{RESULTADOS}

Os métodos de ensino-aprendizagem são coerentes com o curso de engenharia e se inserem bem na disciplina de Operações Unitárias. No semestre de aplicação, as notas dos alunos aumentaram em relação ao semestre anterior, somente com aulas expositivas e avaliações somáticas, pois como tinham que entregar os relatórios de dimensionamento das operações regularmente, este os obrigava a estudar com antecedência a cada conteúdo 
ministrado. Alguns alunos atingiram e reconheceram o aprendizado, porém outros não alcançaram o mesmo propósito. Este fato ocorreu porque a implementação do método apresentou algumas dificuldades que serão abordadas, seguindo como orientação o guia dos sete elementos essenciais para elaboração e desenvolvimento do projeto (Figura 1A).

O problema proposto foi desafiador e o nível dos desafios foi equilibrado com o nível de habilidades e competências dos alunos. A pesquisa foi fundamentada em fontes seguras de informações, em artigos científicos, trabalhos acadêmicos, livros e sites de fornecedores de equipamentos. Segundo Csikszentmihalyi (1988), este é um fator fundamental para uma atividade com motivação, interesse, envolvimento e comprometimento. Entretanto, apesar da facilidade de troca de informação pela internet, alguns dados necessários para os dimensionamentos são muito específicos para o material/produto trabalhado e são difíceis de serem encontradas, necessitando de adaptações para dar continuidade ao trabalho.

Em relação à autenticidade, o projeto contemplava questões do mundo real, ou potencialmente real, porque continha adaptações devido à dificuldade de encontrar uma indústria na área de alimentos que possua todas as operações unitárias a serem trabalhadas, assim, algumas etapas foram ajustadas e não se encaixaram perfeitamente na indústria. Este fato, trouxe grande dificuldade para alguns alunos, porém outros mostraram criatividade e apresentaram soluções alternativas para inserir estas operações. Desta maneira, foi notável que os alunos tiveram voz e tomada de decisões, outro elemento do guia, e desenvolveram habilidades de resolução e estudo autônomo. Todas as operações unitárias necessitaram de tomada de decisão, pois possuíam alternativas para seu dimensionamento, como, por exemplo, escolha da metodologia de cálculo, alocação desta dentre as etapas de processamento e seleção do equipamento a ser utilizado.

No que se refere à reflexão, crítica e revisão, as tarefas e os comentários dos professores sobre as mesmas foram retornadas aos alunos. O ambiente virtual de aprendizagem disponível auxiliou muito para envio de notícias, orientações de estudos, publicações de materiais, envio de trabalho com visualização fácil dos prazos definidos e devolução comentada, sendo essencial para o desenvolvimento da atividade, auxiliando tanto na organização dos alunos quanto dos professores da disciplina. Entretanto, aponta-se como falha, em alguns momentos, a falta de rapidez no retorno aos alunos, necessária para este tipo de procedimento, visto que esta metodologia de aprendizagem exige muita organização e planejamento, tanto dos professores quanto dos alunos, o que algumas vezes não acontece com tanta eficácia por diversos fatores e tem implicações, especialmente, sobre a motivação dos alunos ao longo do processo.

Preconiza-se que as metas estipuladas sejam claras em todas as etapas, sendo fundamental que ambas as partes recebam informações periodicamente sobre o andamento e o desenvolvimento das atividades, permitindo clareza e um balanço sobre o cumprimento dos objetivos propostos. Além disso, esta prática promove comprometimento com os desígnios do processo de aprendizagem e critérios de avaliação, maior discussão e assimilação do conteúdo e monitoramento do próprio aprendizado. Outro ponto a ser comentado é que, apesar dos professores estarem receptivos às críticas e sugestões dos alunos, alguns destes não exprimiam suas questões e obstáculos, dificultando a adoção de estratégias para superá-los. Por fim, o último elemento do guia se refere à apresentação do projeto final, esta foi realizada somente para os professores e alunos da disciplina.

Ainda, analisando o método de acordo com o segundo guia (Figura 1B), em relação ao planejamento e elaboração do projeto, os professores construíram um roteiro e um fluxograma geral para orientação sobre o mesmo, porém alguns alunos relataram que o roteiro não estava claro, necessitando de esclarecimentos sobre o modo de apresentação de cada etapa do trabalho. No que se refere ao gerenciamento das atividades, na maior parte do tempo, este era 
discutido com os alunos, definindo os prazos e datas das avaliações. Entretanto, como o prazo de realização de cada dimensionamento na maioria das vezes foi curto e a forma de apresentação da tarefa não foi suficientemente clara, conforme os alunos comentaram ao final do semestre, o relatório, algumas vezes, era deficiente de informações e comprometia o entendimento e a avaliação dos professores sobre o que foi realizado pelos alunos.

Em relação à construção da cultura e do conhecimento, orientação e envolvimento dos alunos, algumas dificuldades podem ser pontuadas, além das já supracitadas. Muitos alunos declararam estar interessados, em primeiro lugar, na obtenção do diploma, ainda mais por serem disciplinas de final de curso. Outros não possuíam hábitos de estudo e ainda relataram que preferem apenas receber informações passivamente, pois, no modelo tradicional, prestando atenção nas aulas e preparando-se para as provas, e que apenas exigem memorização e imitação, ele demandavam menor esforço e possuíam melhores chances de aparente sucesso. Estes mesmos estudantes, muitas vezes são conscientes da ineficácia do "ensino" assim promovido, mas justificam que o trabalho, estágio e muitos outros compromissos os impedem de estudar. Diante desta realidade, a tentativa de modificação da sala de aula é recebida com desconfiança e resistência.

Além disso, apesar do trabalho em grupo desenvolver competências necessárias a todo profissional, esse exige preparo de formação de alguns alunos para uma mudança de postura perante o professor, os colegas e o processo de aprendizagem, alterando sua posição passiva e individualizada para uma postura ativa e coletiva, o que é difícil no primeiro momento, principalmente quando uma metodologia de aprendizagem diferente da tradicional é empregada em poucas disciplinas do curso. Outra dificuldade do trabalho em grupo é o método de avaliação do conhecimento, e algumas vezes do grau de envolvimento de todos os alunos na atividade. É muito complexo avaliar o desempenho dos alunos de maneira individual dentro do grupo, ainda mais com o tempo curto que se tem para desenvolver todas as atividades propostas na disciplina. Ao final do semestre, alguns se sentiram prejudicados e/ou injustiçados pela forma de avaliação, alegando que tiveram maior comprometimento com o trabalho em relação a outros alunos.

Em vista do exposto, é necessário desenvolver mais a elaboração e implementação da metodologia, a fim de se obter uma aprendizagem mais efetiva; além de construir uma cultura necessária para seu desenvolvimento, tanto da construção autônoma de conhecimento por parte do aluno, quanto do seu relacionamento interpessoal. E ainda, estimular a adoção de metodologias ativas em mais disciplinas ao longo do curso, para que esta construção tenha maior fortalecimento.

\section{CONSIDERAÇÕES FINAIS}

Este método se mostrou coerente com o ensino de engenharia e a disciplina em que foi aplicado, porém é possível observar as vantagens e dificuldades de sua aplicação. Portanto, recomenda-se que seja aprimorado constantemente, semestre a semestre. Neste contexto, a seguir serão enumeradas algumas melhorias que podem ser realizadas neste sentido.

A fim de minimizar a falta de alguns dados na literatura necessários para o material/produto específico e os dimensionamentos, sugere-se maior integração empresaUniversidade, de modo que os alunos, através de visitas técnicas, possam ter acesso a esse material informativo. Adicionalmente, ferramentas computacionais, que otimizem processos e auxiliem na tomada de decisões, também podem ser empregadas para elaborar os cálculos de engenharia e ampliar a aplicabilidade dos conteúdos ministrados. Para aumentar o incentivo e envolvimento dos discentes no processo de aprendizagem e a integração entre os alunos e os 
professores, pode-se utilizar plataformas colaborativas, possibilitando transparência e eficiência para eliminar os ruídos de comunicação entre as partes.

Em relação ao envolvimento dos alunos, deve-se continuar trabalhando e insistindo neste ponto, mesmo com resistência dos mesmos, tanto na forma de estudo quanto no trabalho em grupo. Deve-se mostrar com mais clareza os objetivos do método de ensino-aprendizagem, as instruções da estrutura (roteiro) e método de avaliação do projeto, e ainda a importância da mudança para sua própria formação profissional e pessoal. Felder e Brent (2003) afirmam que quanto mais explicitamente os alunos souberem o que devem fazer, mais vão se esforçar para alcançar o que foi designado e maior será a probabilidade de adquirirem as habilidades desejadas. Além disso, é essencial estimular a adoção de metodologias ativas em mais disciplinas ao longo do curso, para que esta construção tenha maior fortalecimento, como supracitado citado.

Outro fator que pode ser alterado é a forma de avaliação do trabalho tanto dos alunos quanto dos professores ao longo do semestre. Elmôr Filho et al. (2019) citam alguns métodos de avaliação que podem ser aplicados, entre estes, a autoavaliação e pelos pares. A autoavaliação permite que os estudantes pensem com mais atenção em sua postura perante os colegas e em sua aprendizagem, além de poder fornecer ao professor indicativos para auxiliar o desenvolvimento de sua autonomia e também do método de aprendizagem (ELMÔR FILHO et al., 2019), possibilitando ajustes e adaptações ao projeto. Já na avaliação pelos pares pode indicar o comprometimento e o cooperativismo dentro do grupo (ELMÔR FILHO et al., 2019).

Além destas, outras duas avaliações podem ser criadas: uma na forma de ficha para cada tarefa (ou operação unitária), a ser preenchida pelos professores, contendo os aspectos a serem avaliados e de um fator de ponderação, com classificação numérica, para realizar um cálculo final respectivo ao desempenho do trabalho analisado; e outra para apresentação do projeto final (a viabilidade técnica da indústria), que pode ser divulgada aos alunos e professores do curso, para se tornar pública, além de convidar professores de outras áreas ou profissionais atuantes no mercado para avaliarem o trabalho. Este tipo de apresentação possui vantagens e desenvolve competências necessárias aos alunos, tais como capacidade de síntese do conhecimento obtido ao longo do curso, objetividade para mostrá-lo em uma apresentação oral de forma clara para toda a comunidade acadêmica. Estes métodos de avaliação supracitados são complementares, e podem verificar o aprendizado dos estudantes sob diferentes ângulos.

De modo geral, observou-se que a metodologia de aprendizagem baseada em projetos pode estimular os alunos a desenvolverem habilidades, como organização, colaboração, comunicação, autonomia, resolução de problemas e pensamento crítico, estimulando, assim, um aprendizado mais aprofundado e tornando-os construtores ativos de seu próprio conhecimento. Contudo, isso exige uma mudança de postura por parte dos estudantes em relação a comportamento e próprio aprendizado. Não obstante, requer maior dedicação e reflexão dos professores, pois apesar de serem apenas facilitadores neste processo, precisam estar atentos, não somente a cumprir o conteúdo programático, mas também se comprometer com a organização e avaliações contínuas que realmente demonstrem os obstáculos e avanços no processo ensino-aprendizagem alcançados em sua sala de aula.

\section{REFERÊNCIAS}

CONSELHO NACIONAL DE EDUCAÇÃO (Brasília). Resolução nº 02/CNE/CES, de 24 de abril de 2019. Institui as Diretrizes Curriculares Nacionais do Curso de Graduação em Engenharia. Diário Oficial da União: sessão 1, n. 80, p. 43-44, 26 abril 2019. 
CSIKSZENTMIHALYI, Mihaly; CSIKSZENTMIHALYI, Isabella Selega. Optimal experience: psychological studies of flow in consciousness. United Kingdom: Cambridge University, 1988.

ELMÔR FILHO, Gabriel et al. Uma Nova Sala de Aula é Possível - Aprendizagem Ativa na Educação em Engenharia. Rio de Janeiro: LTC, 2019.

FELDER; Richard M.; BRENT, Rebeca. Designing and Teaching Courses to Satisfy the ABET Engineering Criteria. Journal of Engineering Education, v.92, p.7-25, 2003.

GÓMEZ-PABLOS, V.B.; POZO, M.M.; MUÑOZ-REPISO, A.G.V. Project-based learning (PBL) through the incorporation of digital technologies: An evaluation based on the experience of serving teachers. Computers in Human Behavior, v.68, p.501-512, 2017.

PBL Works. The gold standard for high-quality PBL. Disponível em: https://www.pblworks.org/what-is-pbl. Acesso em: 14 maio 2020.

PRINCE, M. Does active learning work? A review of the research. Journal of Engineering

Education, v.93, n.3, p.223-231, 2004.

\title{
APPLICATION ANALYSIS OF PROJECT-BASED LEARNING METHODOLOGY IN THE DISCIPLINE OF THE FOOD ENGINEERING COURSE
}

\begin{abstract}
This work reports the experience of applying project-based learning in the unit operations disciplines of the Food Engineering undergraduate course. The objective is to broaden the methodology knowledge and contribute to future implementations and its systematization. The project sought the contextualized application of the theories studied and the student involvement with group discussions on the issues previously mentioned in class. For their development, the students were divided into small groups, which needed to dimension of the unit operations of a vegetable oil industry. In this process, they need to search for references from different sources, to have critical thinking, good communication, to collaborate with colleagues, and to solve problems, stimulating a more in-depth learning. Although the method is effective for developing these skills, its implementation presented several difficulties, which are analyzed in this work. To overcome them, in the end, corrections and adjustments are also suggested, in order to improve the application of the method and try to achieve the engagement and development of the desired skills in all students in the class. This method, as other active learning methodologies, is dynamic and needs changes throughout the process for its continuous improvement.
\end{abstract}

Keywords: College Education. Active learning methodologies. Collaborative Learning. 